NASA/TM-2010-216743

\title{
Propulsion Health Monitoring of a Turbine Engine Disk Using Spin Test Data
}

Ali Abdul-Aziz

Cleveland State University, Cleveland, Ohio

Mark R. Woike

Glenn Research Center, Cleveland, Ohio

Nikunj Oza and Bryan Matthews

Ames Research Center, Moffett Field, California

George Y. Baaklini

Glenn Research Center, Cleveland, Ohio 


\section{NASA STI Program . . . in Profile}

Since its founding, NASA has been dedicated to the advancement of aeronautics and space science. The NASA Scientific and Technical Information (STI) program plays a key part in helping NASA maintain this important role.

The NASA STI Program operates under the auspices of the Agency Chief Information Officer. It collects, organizes, provides for archiving, and disseminates NASA's STI. The NASA STI program provides access to the NASA Aeronautics and Space Database and its public interface, the NASA Technical Reports Server, thus providing one of the largest collections of aeronautical and space science STI in the world. Results are published in both non-NASA channels and by NASA in the NASA STI Report Series, which includes the following report types:

- TECHNICAL PUBLICATION. Reports of completed research or a major significant phase of research that present the results of NASA programs and include extensive data or theoretical analysis. Includes compilations of significant scientific and technical data and information deemed to be of continuing reference value. NASA counterpart of peer-reviewed formal professional papers but has less stringent limitations on manuscript length and extent of graphic presentations.

- TECHNICAL MEMORANDUM. Scientific and technical findings that are preliminary or of specialized interest, e.g., quick release reports, working papers, and bibliographies that contain minimal annotation. Does not contain extensive analysis.

- CONTRACTOR REPORT. Scientific and technical findings by NASA-sponsored contractors and grantees.
- CONFERENCE PUBLICATION. Collected papers from scientific and technical conferences, symposia, seminars, or other meetings sponsored or cosponsored by NASA.

- SPECIAL PUBLICATION. Scientific, technical, or historical information from NASA programs, projects, and missions, often concerned with subjects having substantial public interest.

- TECHNICAL TRANSLATION. Englishlanguage translations of foreign scientific and technical material pertinent to NASA's mission.

Specialized services also include creating custom thesauri, building customized databases, organizing and publishing research results.

For more information about the NASA STI program, see the following:

- Access the NASA STI program home page at http://www.sti.nasa.gov

- E-mail your question via the Internet to help@ sti.nasa.gov

- Fax your question to the NASA STI Help Desk at $443-757-5803$

- Telephone the NASA STI Help Desk at 443-757-5802

- Write to: NASA Center for AeroSpace Information (CASI) 7115 Standard Drive Hanover, MD 21076-1320 
NASA/TM-2010-216743

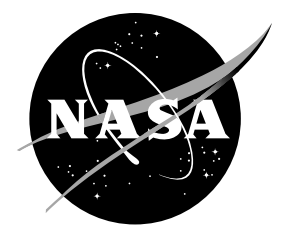

\title{
Propulsion Health Monitoring of a Turbine Engine Disk Using Spin Test Data
}

\author{
Ali Abdul-Aziz \\ Cleveland State University, Cleveland, Ohio \\ Mark R. Woike \\ Glenn Research Center, Cleveland, Ohio \\ Nikunj Oza and Bryan Matthews \\ Ames Research Center, Moffett Field, California \\ George Y. Baaklini \\ Glenn Research Center, Cleveland, Ohio
}

Prepared for the

Smart Structures and Materials and Nondestructive Evaluation and Health Monitoring 2010 sponsored by the International Society for Optical Engineering (SPIE)

San Diego, California, March 7-11, 2010

National Aeronautics and

Space Administration

Glenn Research Center

Cleveland, Ohio 44135 
This report contains preliminary findings, subject to revision as analysis proceeds.

Trade names and trademarks are used in this report for identification only. Their usage does not constitute an official endorsement, either expressed or implied, by the National Aeronautics and Space Administration.

Level of Review: This material has been technically reviewed by technical management.

Available from

NASA Center for Aerospace Information 7115 Standard Drive

Hanover, MD 21076-1320
National Technical Information Service 5301 Shawnee Road Alexandria, VA 22312

Available electronically at http://gltrs.grc.nasa.gov 


\title{
Propulsion Health Monitoring of a Turbine Engine Disk Using Spin Test Data
}

\author{
Ali Abdul-Aziz \\ Cleveland State University \\ Cleveland, Ohio 44115 \\ Mark R. Woike \\ National Aeronautics and Space Administration \\ Glenn Research Center \\ Cleveland, Ohio 44135 \\ Nikunj Oza and Bryan Matthews \\ National Aeronautics and Space Administration \\ Ames Research Center \\ Moffett Field, California 94035 \\ George Y. Baaklini \\ National Aeronautics and Space Administration \\ Glenn Research Center \\ Cleveland, Ohio 44135
}

\begin{abstract}
On line detection techniques to monitor the health of rotating engine components are becoming increasingly attractive options to aircraft engine companies in order to increase safety of operation and lower maintenance costs. Health monitoring remains a challenging feature to easily implement, especially, in the presence of scattered loading conditions, crack size, component geometry and materials properties. The current trend, however, is to utilize noninvasive types of health monitoring or nondestructive techniques to detect hidden flaws and mini cracks before any catastrophic event occurs. These techniques go further to evaluate materials' discontinuities and other anomalies that have grown to the level of critical defects which can lead to failure. Generally, health monitoring is highly dependent on sensor systems that are capable of performing in various engine environmental conditions and able to transmit a signal upon a predetermined crack length, while acting in a neutral form upon the overall performance of the engine system. Efforts are under way at the NASA Glenn Research Center through support of the Intelligent Vehicle Health Management Project (IVHM) to develop and implement such sensor technology for a wide variety of applications (Refs. 1 to 5). These efforts are focused on developing high temperature, wireless, low cost and durable products.

Therefore, in an effort to address the technical issues concerning health monitoring of a rotor disk, this paper considers data collected from an experimental study using high frequency capacitive sensor technology to capture blade tip clearance and tip timing measurements in a rotating turbine engine-likedisk-to predict the disk faults and assess its structural integrity. The experimental results collected at a range of rotational speeds from tests conducted at the NASA Glenn Research Center's Rotordynamics Laboratory are evaluated using multiple data-driven anomaly detection techniques (Refs. 11 to 15) to identify anomalies in the disk. This study presents a well rounded evaluation of an online health monitoring of a rotating disk using these high caliber sensors and test the capability of the in-house spin system.
\end{abstract}




\subsection{Introduction}

Health monitoring of critical turbine engine components is becoming a high interest topic among engine companies and associated aviation industry. Generally, health monitoring is conducted via sensor systems that are capable of functioning in a harsh environment and able to transmit a signal upon detecting the presence of a dominant crack. These systems must operate in a neutral fashion and cause no interference to the overall performance of the engine system. However, developments and accomplishment of this technology are dependent on various factors which include running parallel analytical and experimental studies to assess their applicability and success. Such efforts are under way to pursue this endeavor technology which covers high temperature, wireless, low cost and durable sensors for a wide variety of hot engine applications (Refs. 1 to 5).

Other means of inspections and health monitoring are available through nondestructive evaluation (NDE) techniques which are typically used to perform periodic checkups during major engine overhauls to locate any cracks that may have formed and to prevent premature catastrophic failure (burst) of the engine. However, some if not most of these techniques can be both costly and impractical to inspect such complex geometries and large components. Among those available techniques is the Fluorescent Penetrant Inspection (FPI) which is the lowest from a cost point of view. However, FPI often fails to disclose cracks that are tightly closed during rest or that are below the surface. The next system that can be most effective is the eddy current approach which can detect cracks along and below the surface, but it requires careful setup and operation, while allowing only a small portion of the disk to be practically inspected. Therefore, the need for more reliable diagnostic tools and high level techniques for damage detection and health monitoring of rotating components is of extreme importance and highly fundamental to maintaining engine safety, reliability and life assessment (Ref. 5).

The NASA Aviation Safety Program is aware of these concerns and is actively working on promoting the development of technologies that would contribute towards a reduction in the fatal aviation accidents and assist in improving safety as a whole. It is a team effort that includes a partnership between NASA, the Federal Aviation Administration (FAA), the aviation industry and the Department of Defense (Ref. 4). This has motivated the Optical Instrumentation and NDE Branch at the NASA Glenn Research Center at Lewis Field to consider taking on a constructive role to help develop health monitoring technologies to detect rotor damage prior to any catastrophic events in support of these research plans (Refs. 5 and 6). This role consists of running controlled spin tests to investigate and implement various sensing innovations for local and global detection of rotor damage. These tests will incorporate performing systematic evaluation of crack detection methodologies through management of highly controlled crack initiation and growth tests. Rotors test articles resembling turbine engine disk are to be spun at rotational speeds up to $12,000 \mathrm{rpm}$. Comparison of test data for baseline disks without any damage with those having an artificially induced damage (notch) will be conducted to appraise the findings. The subject of crack detection has been addressed by many researchers where vibration response of a cracked rotor passing through the critical speed is examined utilizing a simple hinge model for small cracks (Refs. 8 to 10). Bently (Ref. 9) presented a rotor crack detection procedure based on the start-up and shutdown vibration monitoring.

This paper presents a summary and discussion of the results obtained from a joint analyticalexperimental study that included spin testing of a rotor disk along with a detailed output from a multiple data-driven anomaly detection techniques to identify the anomalies in the rotor (Refs. 11 to 14). Experimental results collected at a range of rotational speeds from tests conducted at the NASA Glenn Research Center's Rotordynamics Laboratory are used to identify and verify crack detection methods using these multiple technical approaches. Results reported are discussed and evaluated. This study presents a select evaluation of online health monitoring of rotating disks with emphasis on comparing crack detection algorithms, simulated analytical crack detection settings and the latest up-to-date sensor technology along with a high caliber in house spin testing system. 


\subsection{Technical Approach}

\subsection{Capacitive Probe Sensor Technology}

The capacitive sensors are designed to monitor the electrical property of "capacitance" to initiate and take measurements. Capacitance is defined as a field that exists between two conductive surfaces within some rational proximity. Variations in the distance between the surfaces lead to changes in the capacitance rate. This capacitance rate change is used by the sensors to indicated difference in position of a target. High-performance displacement sensors use small sensing surfaces and as result are positioned close to the targets $(0.25$ to $2 \mathrm{~mm})$.

Figure 1 shows the disk specimen and the induced crack-notch along with the tip clearance probes. The test specimen disk has an outside diameter of $23.495 \mathrm{~cm}$ (9.25 in.) respectively; a bore and an outside rim thickness of $2.54 \mathrm{~cm}$ ( 1 in.) and $3.175 \mathrm{~cm}$ (1.25 in.); the thickness of the web is $0.254 \mathrm{~cm}(0.10 \mathrm{in}$.$) ,$ and the cross section and height of the blades are $3.175-$ by $0.330-\mathrm{cm}(1.25-$ by $0.13 \mathrm{in}$.) and $0.838 \mathrm{~cm}$ (0.33 in.), respectively. It has rotor like blades, total of 32, evenly spaced around the circumference. Eight holes, $0.508 \mathrm{~cm}(0.20 \mathrm{in}$.) diameter each, were drilled through the disk half-way in the rim. The holes were spaced every $45^{\circ}$ and they were designed for future studies as possible mass add-on points or notch initiation sites.

The materials used to manufacture the disk specimen were nickel base alloy Haynes X-750 and Grade 2-Titanium. This paper focuses on the Haynes X-750 material disk which weighs approximately $10.75 \mathrm{lb}(4.88 \mathrm{~kg})$. For blade tip clearance measurements, a capacitive sensor system was installed, see Figure 1. These types of sensors are based on a DC offset rather than a modulation technique. The DC voltage, in conjunction with the motion of the rotor, allowed the current system to record three channels at a rate of $1 \mathrm{MHz}$ each. The experimental testing included running tests under transients and steady state conditions such as ramp-up, ramp-down and cruise conditions.

The controlled speed applied during the current testing ranged from a minimum of 1,000 up to a maximum of 10,000 rpm with acceleration-deceleration rates of $60 \mathrm{rpm} / \mathrm{second}$. This insured surpassing the critical speed of 2,610 rpm and leading to post critical state. Experiments covered base line runs with undamaged disk and with damaged disk via artificially induced notch, shown in Figure 1.

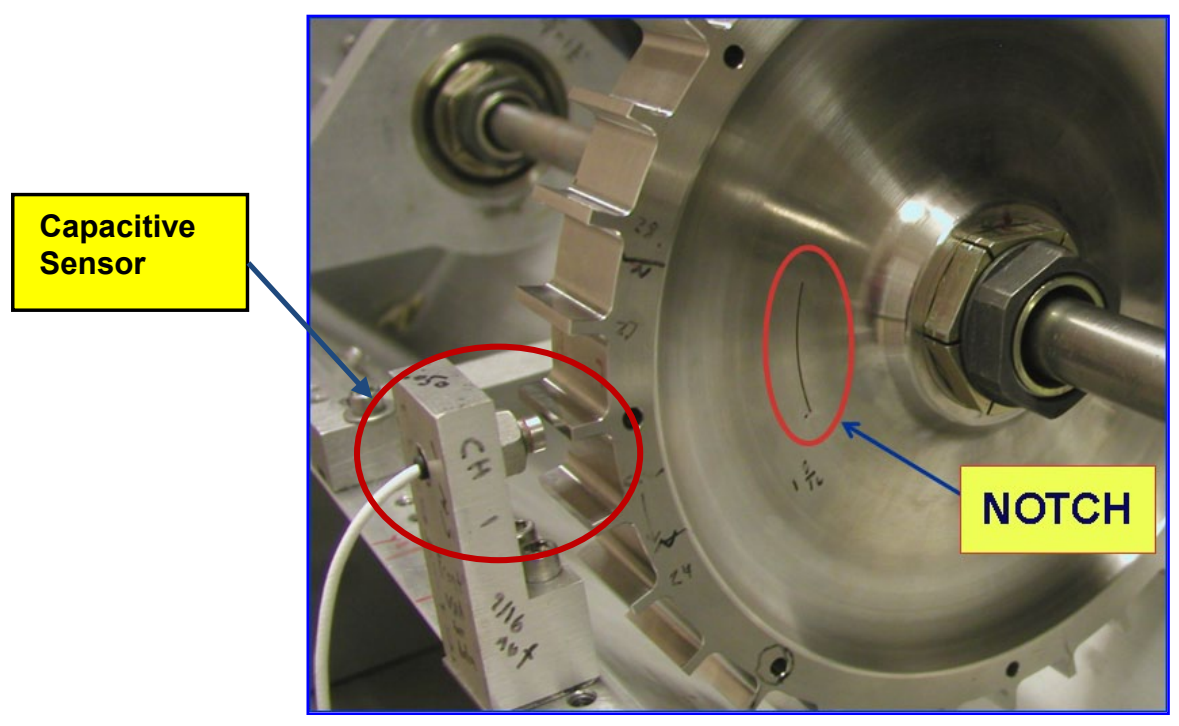

Figure 1.-Test disk with a notch. 


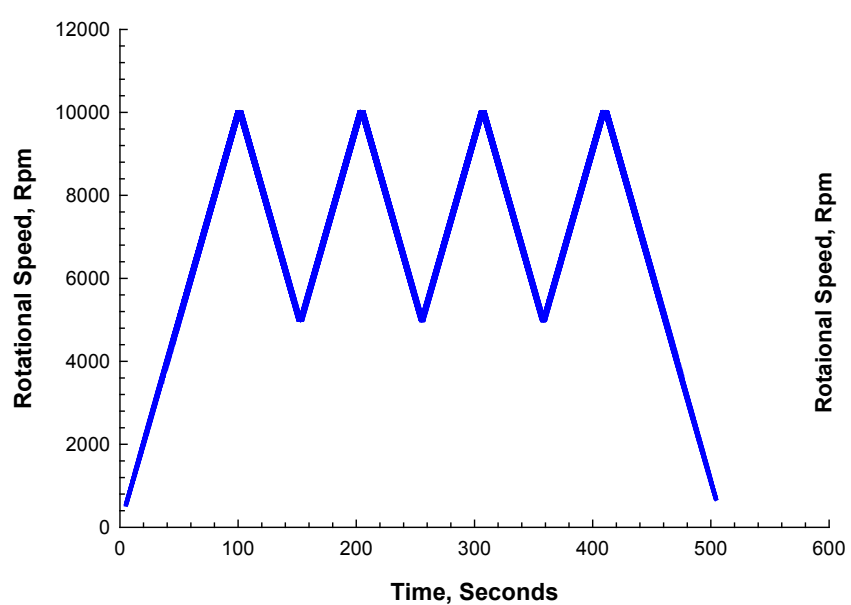

(a) Constant amplitude

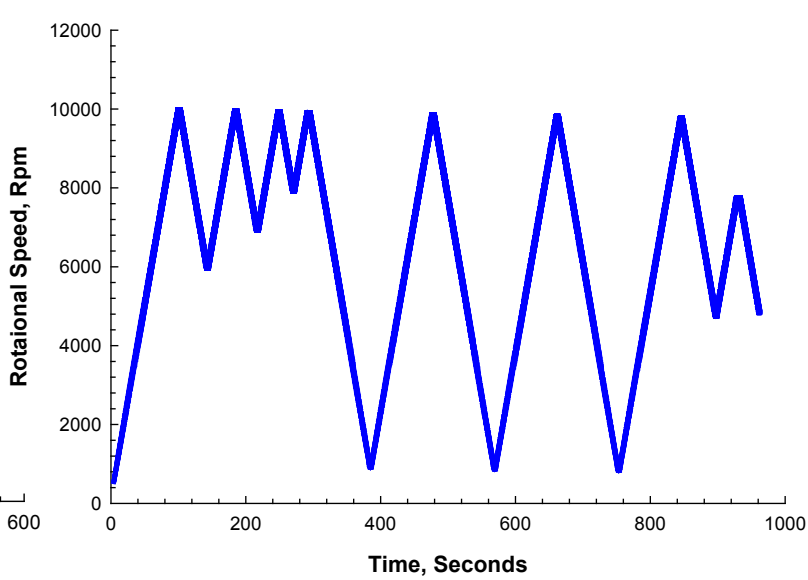

(b) Variable Amplitude

Figure 2.-Simulated engine mission history profiles.

The notch had a width of $0.381 \mathrm{~mm}(0.015 \mathrm{in}$.) as per wire thickness and burn area of the electric discharge machining (EDM) process. The notch region was intentionally selected to be in the rim area due to the fact that the finite element results revealed that this section encounters the highest stress level in the disk during the spin operation (Refs. 1 and 2). Systemic considerations were emphasized to preserve consistency of the operating parameters and other experimental conditions during the removalreinstallation process of the disk specimen in both situations, baseline no-notch and notch state.

Figure 2 shows the mission history profiles applied in this experimental work for the disks, the baseline unnotched and the notched disk. These profiles were derived on the basis of revolutions per minute data obtained on different flights comprising different flight maneuvers (Ref. 15). Figure 2(a) shows the constant amplitude portion which is one of the test mission profiles applied in the experiment. It clearly demonstrated less aggressive and smoother profile compared to the variable amplitude profile shown in Figure 2 (b), starting with a minimum of $200 \mathrm{rpm}$ up to a maximum of 10,000 and a shutdown to $0 \mathrm{rpm}$. Meanwhile, Figure 2(b) represents the variable amplitude engine history which reflects steep and sharp changes in the rotational speed across the entire cycle, subjecting the disk to high and complex loading conditions in an attempt to fatigue the disk with the expectation that all existing anomalies would appear in the test data. The speed was varied sharply from a minimum of $200 \mathrm{rpm}$ up to $10,000 \mathrm{rpm}$ at various intervals. Testing the rotor under these conditions provided a good simulation to collect data under various loading conditions which the disk may experience during nontypical operating environment. Furthermore, these experiments supplied valuable assessments for both, the crack detection scheme and the structural durability of the disk materials.

Experimental data under both applied mission profiles are represented in Figures 3 and 4. The data in Figure 3 are produced under the constant amplitude mission for both the baseline no-notch and the notched disks. The mission history is shown along with the trace vibration vector and bode plots for the phase and amplitude response. A clear observation is noted for both, the baseline and the notched disk; a closed loop representation for the trace of vibration vector is seen for the baseline disk while a gap in the loop is present for the notched disk. This behavior offers the first hint that we have a difference in the vibration response for the two structures indicating the presence of some type of anomaly. Such observation has been reported in Reference 7, where a crack in the rotor disk is documented via the presence of distorted trace of the vibration vector distribution and a rise in the phase and amplitude response upon surpassing the critical speed stage. 


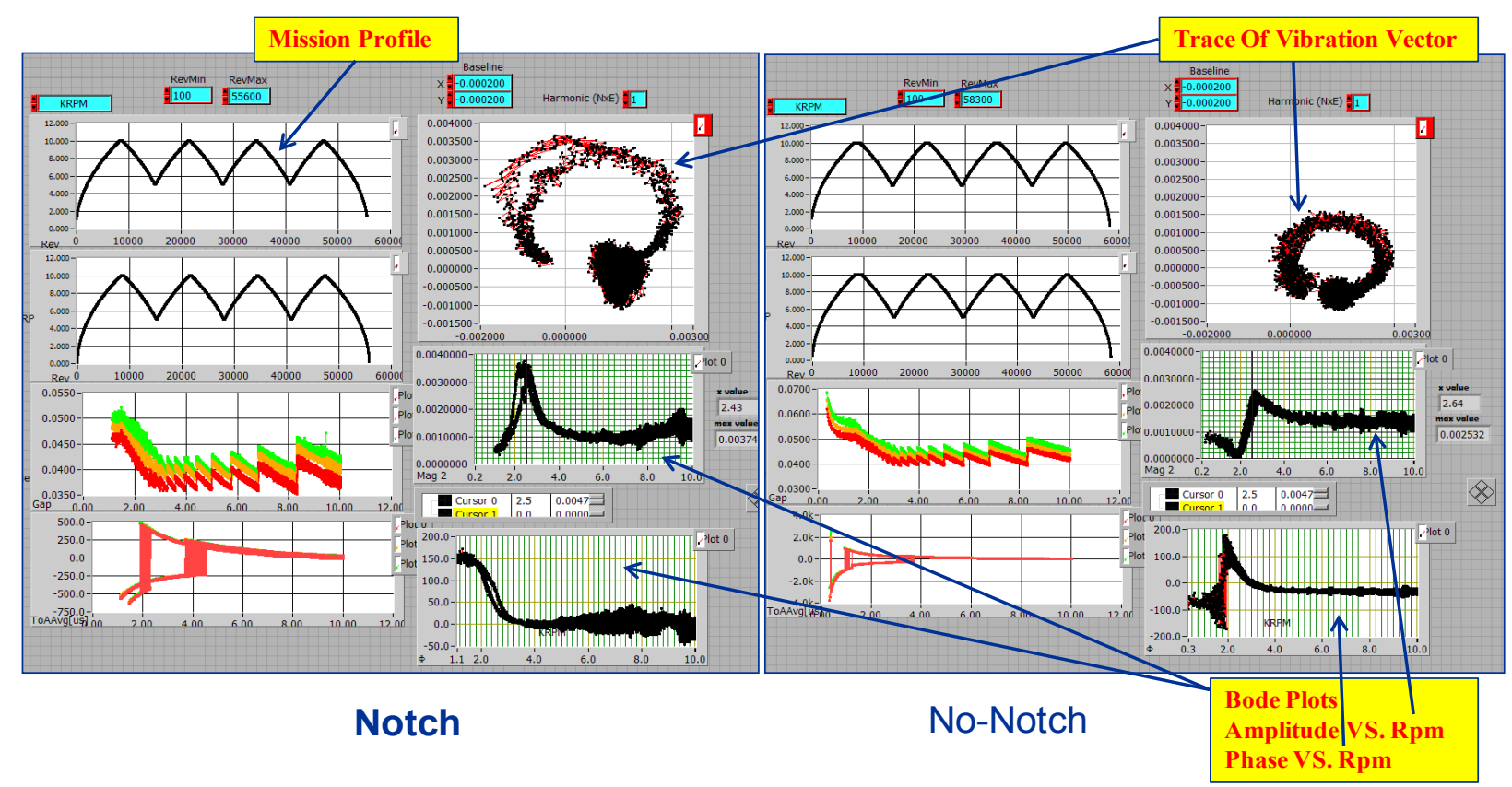

Figure 3.-Bode Plots-9 minutes comparison test for the disk with and without notch, constant amplitude mission profile.

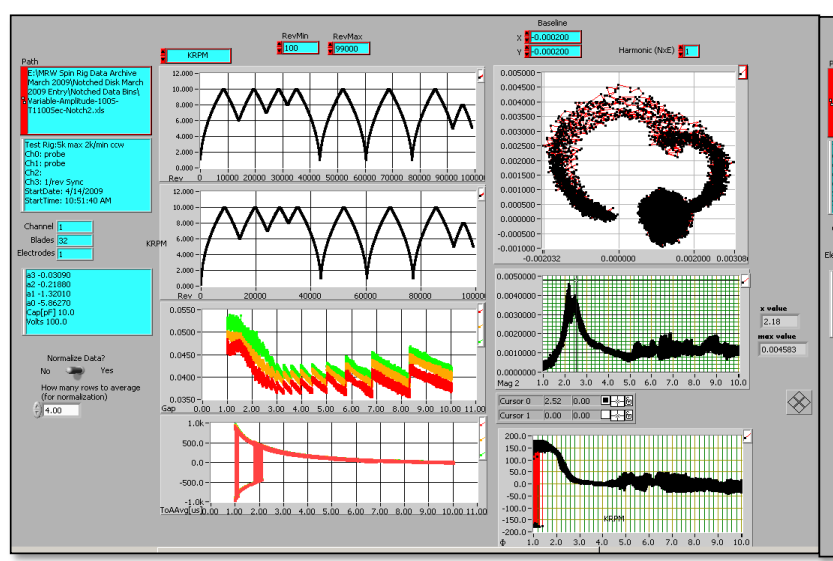

Notch
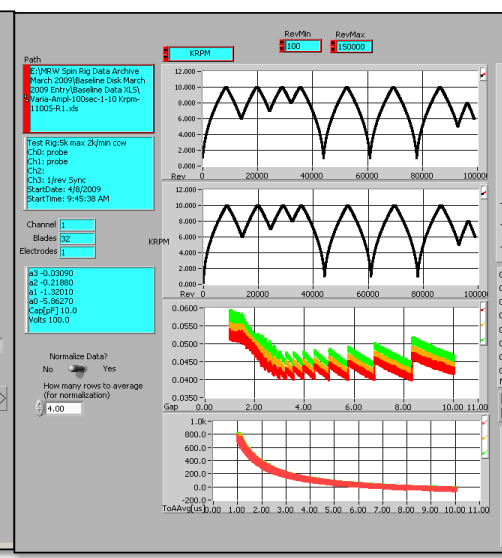

No-Notch

Figure 4.-Bode Plots-9 minutes comparison test for the disk with and without notch, variable amplitude mission profile.

This conduct is obvious in Figure 3 for the notched disk. A rise in the phase and amplitude response is clearly noted. While a flat and steady decrease in these parameters is shown for the baseline rotor which implies that it is a healthy rotor. Again, similar remarks for the variable amplitude mission history profile are seen in Figure 4. A rise is reported in the phase and amplitude response as soon as the disk crosses the 5,000 rpm level up to the 9,000 rpm where a notable no changes response is apparent. The difference between the data reported for the variable and the constant amplitude profile is confined to a higher blade tip clearance for the variable amplitude (nearly about 22 percent higher). Therefore, examination of the above data verified that the detection scheme applied in the experiment seemed to deliver a reasonable set of results indicating the presence of a defect in the rotor disk. However, this confirmation has to be further documented by conducting more tests for different rotors under similar operating conditions to authenticate that this behavior in the data is strictly due to existing structural defects in the rotor and not due to a system related unbalance. 
In addition to the experimental work and to complement the findings, additional or parallel health monitoring assessments of the rotors were conducted using other nonexperimental approaches. Three different techniques were applied: Orca, IMS and OCSVM (Refs. 11 to 14). These techniques were simply limited to employing simulation type analysis to examine the experimental data under the same operating conditions employed in the tests and using the data collected (blade tip clearance) as a key input to the analytical simulation to check the viability of the detection techniques and to evaluate the performance of each methodology. These methodologies provide a method that can monitor the health of a system based on a certain fidelity which trains the model to identify normal system parameters from abnormal ones. This is implemented by defining groups of consistent system parameter data via examining and generalizing from examples of nominal system data. With extensive training data set, the knowledge based produced by these techniques should have most or all of the consistent parameter value combinations to effectively portray and monitor nominal system operation. Upon learning how the system should behave under nominal operating conditions, these data analyses techniques could easily identify abnormal behavior and display faulty message to the system operators. Three phases of simulation analyses were conducted for each test mission cycle applied. They are described in some details in the subsequent subsections.

\subsection{Detection Algorithms}

\section{$3.1 \quad$ Orca}

Orca (Ref. 12) is an outlier detection algorithm which uses the Euclidean distance nearest neighbor based approach to determine outliers. For computational efficiency, it employs a modified pruning technique which allows it to perform in near linear time. For each point in the test data set, where a point is a row in the data set consisting of measurements taken at a single point in time which is in general consists of displacements quantity, Orca calculates the nearest neighbor points from the reference data set. The output from Orca is a distance score which represents the average distance to its k-nearest neighbors; the more anomalous the point is the higher the score, since the nearest neighbors are farther away. More information about this algorithm can be found in Reference 12 .

\subsection{Inductive Monitoring System (IMS)}

IMS is a cluster based modeling method. The algorithm is given a set of nominal data points and builds a model by agglomerative clustering of the data points. The resulting model is used to generate anomaly scores for new data. For each test data point, IMS finds its distance to the nearest cluster's boundary. The score that is reported is the sum of the squares of the distances from the test data point to the dimensional bounds of the closest cluster. If a data point falls entirely within the cluster bounds, it is assigned a score of zero. More information about IMS can be found in Reference 11.

\subsection{One-Class Support Vector Machine (OCSVM)}

OCSVM is a one-class nonlinear kernel based algorithm that maps the training data to a higherdimensional feature space and then linearly separates nominal data from anomalies in that feature space. The idea is that such a model corresponds to a nonlinear model in the original data space, but still maintains the benefit of a linear model in that it is guaranteed to return the model with the lowest error over the training set. The algorithm identifies a subset of the training data (called the "support vectors"), which is used to generate a hyperplane model. The anomaly score that is reported is the distance from the test data point to the hyperplane as measured in the feature space. More information on OCSVM can be found in References 13 to 14. 


\subsection{Cycle Runtime Procedure}

Figure 5 through 8 provides the scores for the three different techniques. In Figures 6 and 8 the anomaly scores are portrayed as positive values and any nominal points are represented as zero. This was done to allow for similar comparison across the algorithms. It is important to note that OCSVM allows some nominal sample points in the training set to be classified as anomalous. This percentage is governed by the $\mathrm{Nu}$ parameter, which is set by the user, but for which we set currently at the default value of 10 percent. Due to this characteristic of the algorithm, 10 percent of all nominal data tested may result in anomalous classification. In Tables 1 and 2 the choice for fixing correct classification to 90 percent was to make the comparisons fair between all three algorithms, since OCSVM, in this case, was optimized for a correct classification of 90 percent.

TABLE 1.-CONSTANT AMPLITUDE-5,000 TO 10,000 RPM RESULTS

\begin{tabular}{|l|l|c|c|c|c|}
\cline { 2 - 6 } \multicolumn{1}{c|}{} & \multicolumn{1}{c|}{ Algorithm } & $\begin{array}{c}\text { Correct detection rate, } \\
\%\end{array}$ & $\begin{array}{c}\text { False alarm rate, } \\
\%\end{array}$ & $\begin{array}{c}\text { Accuracy, } \\
\%\end{array}$ & Area under ROC \\
\hline \multirow{2}{*}{$5 \%$ false } & Orca & 100 & 5 & 97.55 & 1.00 \\
alarm rate & IMS & 93 & 5 & 94.02 & 0.93 \\
& OCSVM & 100 & 5 & 97.55 & 0.99 \\
\hline \multirow{2}{*}{$90 \%$ correct } & Orca & 90 & 0.58 & 94.62 & 1.00 \\
detection & IMS & 90 & 0.36 & 94.73 & 0.93 \\
& OCSVM & 90 & 1.26 & 94.28 & 0.99 \\
\hline
\end{tabular}

TABLE 2.-VARIABLE AMPLITUDE CYCLE-1,000 TO 10,000 RPM DATA

\begin{tabular}{|l|l|c|c|c|c|}
\cline { 2 - 6 } \multicolumn{1}{c|}{} & \multicolumn{1}{c|}{ Algorithm } & $\begin{array}{c}\text { Correct detection rate, } \\
\%\end{array}$ & $\begin{array}{c}\text { False alarm rate, } \\
\%\end{array}$ & $\begin{array}{c}\text { Accuracy, } \\
\%\end{array}$ & Area under ROC \\
\hline \multirow{2}{*}{$5 \%$ false } & Orca & 100 & 5 & 98.33 & 0.99 \\
alarm rate & IMS & 87 & 5 & 89.82 & 0.87 \\
& OCSVM & 99 & 5 & 98.28 & 0.99 \\
\hline \multirow{2}{*}{$90 \%$ correct } & Orca & 90 & 1.99 & 92.68 & 0.99 \\
detection & IMS & 90 & 2.96 & 59.88 & 0.87 \\
& OCSVM & 90 & 92.36 & 0.99 \\
\hline
\end{tabular}
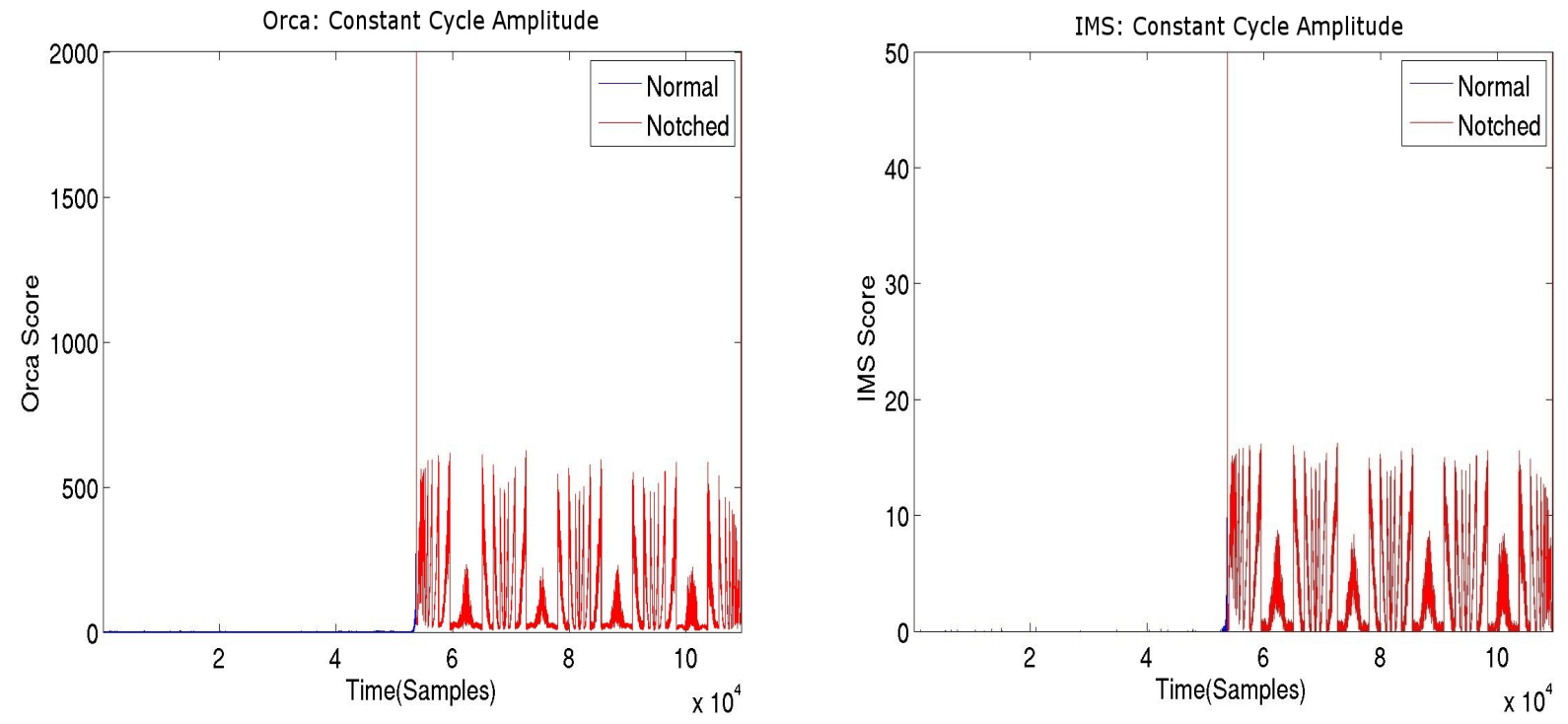

Figure 5.-Results of Data Driven Anomaly Detection Technique; ORCA and Inductive monitoring system (IMS). 


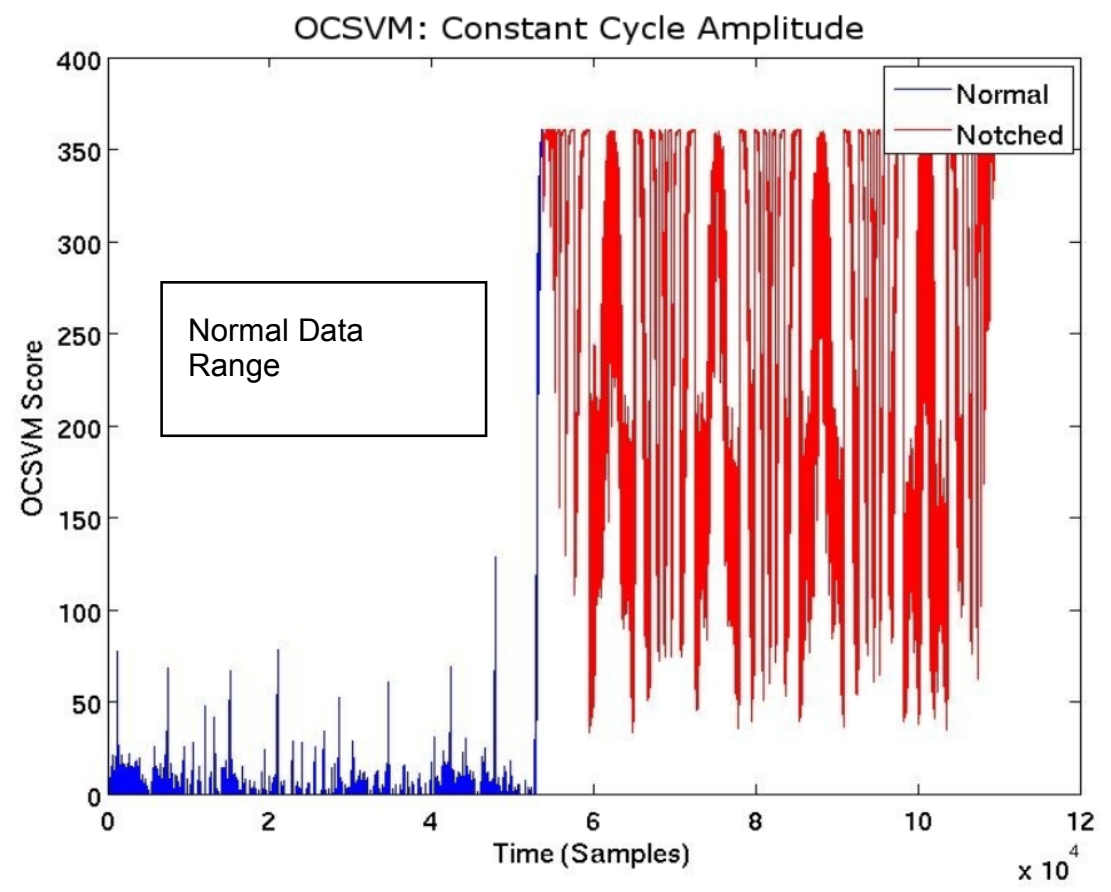

Figure 6.- Results of Data Driven Anomaly Detection Technique; OCSVM Algorithm.
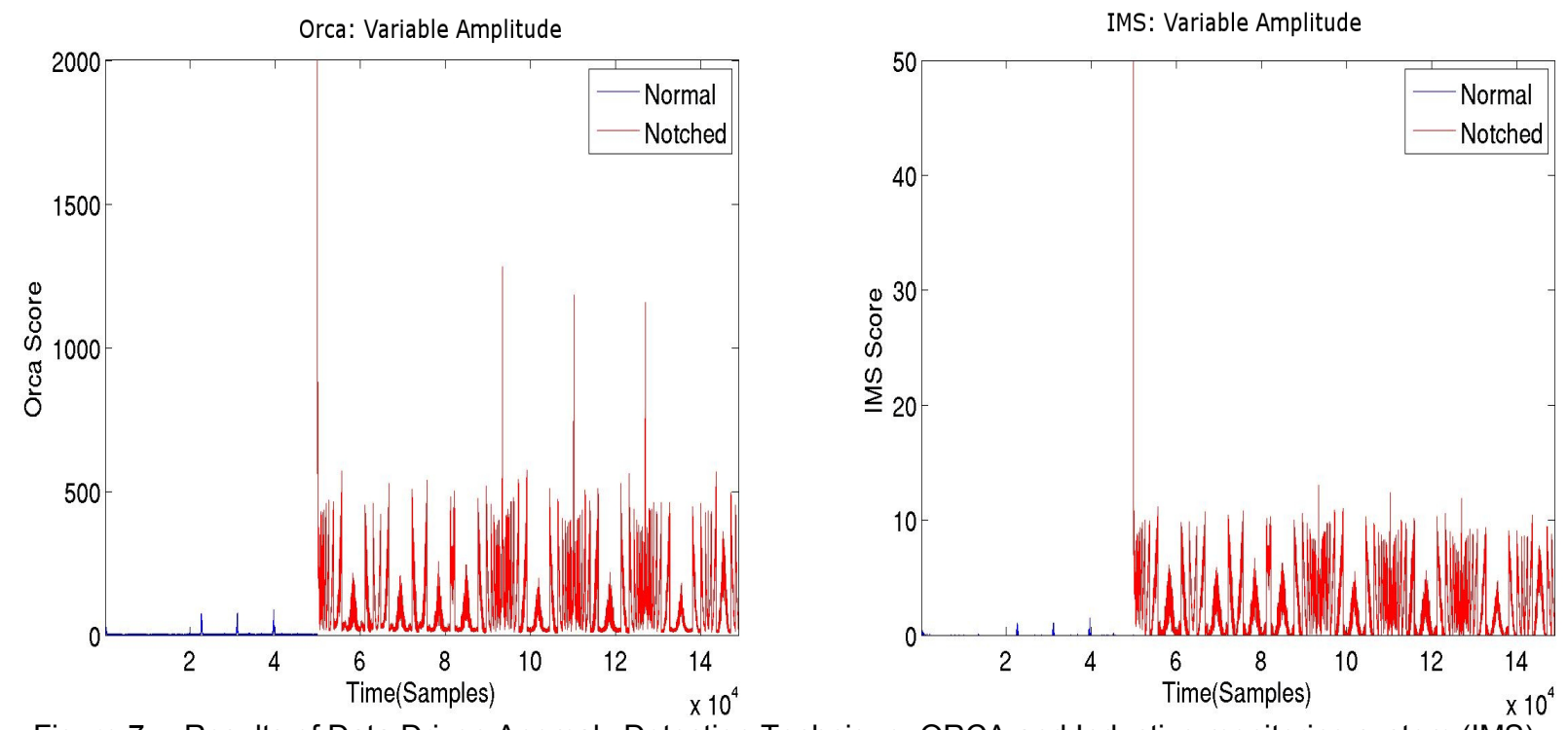

Figure 7.-Results of Data Driven Anomaly Detection Technique; ORCA and Inductive monitoring system (IMS). 


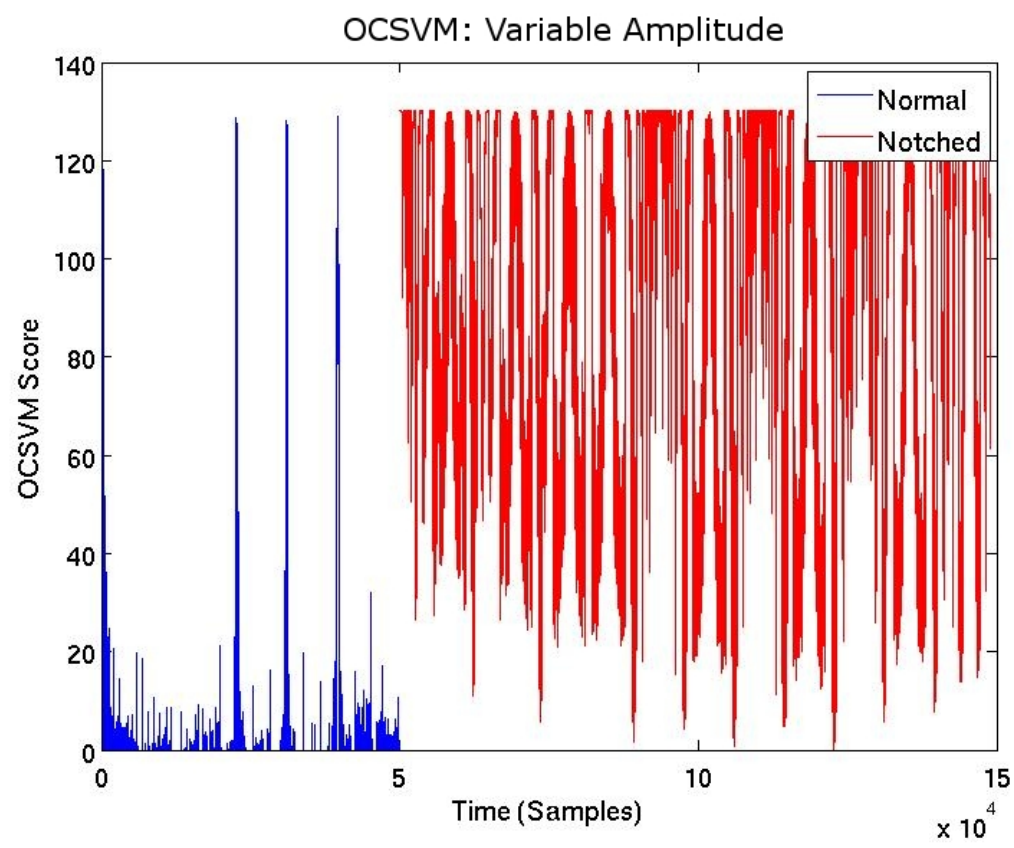

Figure 8.-Results of Data Driven Anomaly Detection Technique; One-Class Support Vector Machines (OCSVM).

\subsection{Analysis-Results}

\subsection{Constant Amplitude Cycle Runtime Procedure}

For the constant amplitude cycle (Fig. 2(a)) data analysis, the data was recorded in two sets: "normal" and "notched". The rotational speed for the disk continuously varied from 5,000 to 10,000 rpm for both normal and notched runs. In this analysis, only the 32 gap measurements were considered. Orca, Inductive Monitoring System (IMS) and One-Class Support Vector Machines (OCSVM) were chosen to evaluate this data. The normal run's data was randomly divided in half. One half was used for training and the remainder half was used for validation. The means and standard deviations for all 32 channels are calculated for the training data and used to z-score normalize (normalize each channel to have zero mean and unit standard deviation) both the training and testing data sets. The plots, Figures 5 to 8 , are the global anomaly scores for each of the algorithms on both the validation normal and the notched runs over time.

\subsection{Variable Amplitude Cycle Runtime Procedure}

An additional data set had rotational speed varying from 1,000 to 10,000 rpm; Figure 2(b) was evaluated using all three algorithms. For the analysis of 1,000 to 10,000 rpm data, the algorithms performed comparably to the 5,000 to $10,000 \mathrm{rpm}$ analysis. However, in the category of false alarm rates when fixing the correct detection at 90 percent IMS appears to have trouble, with a false alarm rate of 100 percent. It also appears that Orca has an edge in this category with a false alarm rate of 1.99 percent where OCSVM is slightly higher at 4.57 percent.

It is also important to note that Orca and OCSVM performed well when fixing the false alarm rate at 5 percent, which results in a 100 percent correct detection rate. The correct detection rate is defined as the percentage of faulty sample points that fall above a fixed threshold and are correctly identified as faulty. A correct detection rate of 100 percent does not necessarily imply that the false alarm rate is 0 percent, 
since the false alarm rate is defined as the percentage of nominal sample points that fall above the same threshold and are labeled faulty. False alarms may still be present if there is an overlap in score magnitudes between faulty and nominal sample points. In this case a threshold was chosen that yielded 5 percent false positives and resulted in 100 percent correct detection. The area under the ROC curve parameter also shows a slightly better performance for Orca and OCSVM with areas of 0.99 and 0.95 respectively than IMS's area of 0.87 , see Table 2 .

Therefore, based on the information reported in Figures 5 to 8, it can be concluded that the detection techniques performed as expected and indications of malfunctions are seen in the scored representations of highly spiked distributions for the notched disk, while no spikes are noted for the baseline no notch disk. This applies to the data reported in Figures 5 to 8 . The evaluation of the data reported from these techniques is also tied to the scores produced as a result of the simulation. For instance, the higher the score, the more anomalous is the structure.

All three algorithms appear to perform quite well in distinguishing between the notched disk run and the hold out nominal data. Orca and OCSVM seem to show slightly better numbers across a few of the metrics. In Table 1 the metrics used for comparison are correct detection, false alarm rate, accuracy, and area under the Receiver Operating Characteristic (ROC) curve, ROC stands for Receiver operating characteristic. It is a plot of false positives versus true positives. The ideal curve is one that has a 90 bend in it shooting straight up with the false positive $=0$ and holding the true positive $=1$ across resulting in an area of 1.00. When fixing the false alarm rate at 5 percent, Orca and OCSVM both have 100 percent correct detection rate of the notched anomalous data, where IMS's correct detection rate is at 93 percent. When fixing a threshold so that the correct detection rate is 90 percent, all three show very good false alarm rates, see Table 1. An additional metric, that is independent of choosing a threshold, is measuring the area under the ROC curve. When comparing this metric across the three algorithms, all three methods are reporting very good areas with Orca and OCSVM doing slightly better than IMS.

\section{Conclusions}

A health monitoring study of a turbine-engine-like rotor disk was conducted through combined experimental and data-driven anomaly detection techniques. The extent of the work involved conducting simulation spin tests on turbine-engine-like rotors with and without an artificially induced notch at different rotational loading levels. Bode plots of data from these tests provided indications of differences induced by the fault. Additional health monitoring verification/evaluation was performed by using three different automatic data-driven detection algorithms: Orca, OCSVM and IMS. These techniques were simply limited to employing simulation type analysis to examine the experimental data under the same operating conditions employed in the tests data collected (blade tip clearance) was used as a key input to the analytical simulation to check the viability of the detection techniques and to evaluate the performance of each methodology. Two different engine mission profile cycles were evaluated which covered variable amplitude and constant amplitude type speed variation where the rotational speed was varied from a minimum of 1,000 to $10,000 \mathrm{rpm}$ at different time intervals. The results obtained showed that the detection algorithms are capable of predicting anomalies in the rotor disk with very good accuracy. Each detection scheme performed differently under the same experimental conditions and each delivered a different level of precision in terms of detecting a fault in the rotor. Overall rating showed that both the Orca and OCVSM performed better than the IMS technique.

Furthermore, the experimental data acquired proved to be crucial in assisting data-driven anomaly detection techniques in assessing the health conditions of the rotor disk. The experimental data added more information about the crack detection scheme applied. It showed that the blade tip clearance tends to be higher upon existence of a notch. Bode plots offered more asserting results concerning the crack detection. This is noted for both, the baseline and the notched disk; a closed loop representation for the trace of vibration vector is seen for the notch disk while a gap in the loop is present for the notched disk. This behavior offers the first hint that we have a difference in the vibration response for the two structures indicating the presence of some type of anomaly. However, additional work and testing must be 
continued to develop, improve and link this combined analytical-experimental tool to offer a more precise and accurate appraisals of the health of rotating components. One last note, although this work is still in its early stages, however it is very promising and the expectation to put it this into a practical crack detection technology is quite high.

\section{References}

1. Ali Abdul-Aziz, G. Abumeri, Mark Woike and George Baaklini ,'NDE Using Sensor Based Approach to Propulsion Health Monitoring of a Turbine Engine Disk", submitted for presentation at the SPIE Smart Structure/NDE, 8-12 March 2009, San Diego, CA.

2. Ali Abdul-Aziz, Mark Woike, John Lekki and George Y. Baaklini;" Health Monitoring of a Rotating Disk Using a Combined Analytical-Experimental Approach," NASA Technical Memorandum, NASA/TM-2009-215675, Sep. 2009.

3. Abdul-Aziz, A., R.T. Bhatt and G.Y Baaklini; "Criteria for Crack Deflection/Penetration in Coated Ceramics; a Parametric Study". Proceedings the $14^{\text {th }}$ SPIE's Annual International Symposium on Nondestructive Evaluation for Health Monitoring and Diagnostics, Mar. 18-22, 2007, San Diego, CA.

4. Abdul-Aziz, A., David. J. Krause; "Combined Experimental and Analytical Study Using Cruciform Specimen for Testing Advanced Aeropropulsion Materials Under In-Plane Biaxial Loading," Proceedings the $11^{\text {th }}$ SPIE's Annual International Symposium on Nondestructive Evaluation for Health Monitoring and Diagnostics, Feb. 26-Mar. 2, 2006, San Diego, CA.

5. Abdul-Aziz, A., C. Saury, Bui Xuan, P.G. Young; "On The Material Characterization of a Composite using Micro CT Image Based Finite Element Modeling," Proceedings the $11^{\text {th }}$ SPIE's Annual International Symposium on Nondestructive Evaluation for Health Monitoring and Diagnostics, Feb. 26-Mar. 2, 2006, San Diego, CA.

6. Abdul-Aziz, A., J. J. Trudell, George Y. Baaklini; "Finite Element Design Study of a Bladed, Flat Rotating Disk to Simulate Cracking in a Typical Turbine Disk, Part II" Proceedings the $11^{\text {th }}$ SPIE's Annual International Symposium on Nondestructive Evaluation for Health Monitoring and Diagnostics, Feb. 26-Mar. 2, 2006, San Diego, CA.

7. Wayne C. Hass and Michael J. Drumm;'Detection, Discrimination and Real-Time Tracking of Cracks in Rotating Disks," IEEE, 2002

8. Sekar, A.S., Prabhu, B.S., Condition Monitoring of Cracked Rotors Through Transient Response, Mechanism and Machine Theory, Vol. 33, Issue 8, pp. 1167-1175, 1998.

9. Bentlty, D.E, "Detecting Cracked Shafts at Earlier Levels, Orbit Magazine, "Bently, NV, Vol. 3, No. 2, 1982.

10. Wauer, J., On the Dynamics of Cracked Rotors: A literature Survey, Applied Mechanics Review, Vol. 43(1), pp. 13-17, 1990.

11. Iverson, D.L., "Inductive System Health Monitoring," Proceedings of the International Conference on Artificial Intelligence, IC-AI '04, Vol. 2, Proceedings of the International Conference on Machine Learning; Models, Technologies \&Applications, MLMTA ’04, Jun. 21-24, 2004.

12. Bay, S.D., and Schwabacher, M., "Mining Distance-Based Outliers in Near Linear Time with Randomization and a Simple Pruning Rule," Proceedings of the Ninth ACM SIGKDD International Conference on Knowledge Discovery and Data Mining. Association for Computing Machinery, New York, NY, 2003.

13. Tax, D.M.J. and Duin, R.P.W., "Support Vector Domain Description," Pattern Recognition Letters, Vol. 20, No. 1113, pp. 1191-1199, 1999.

14. Scholkopf, B., Platt, J.C., Shawe-Taylor, J., Smola, A.J., and Williamson, R.C. "Estimating the Support of a High-Dimensional Distribution," Neural Computation, Vol. 13, No. 7, 2001, pp. 1443-1471.

15. Ashok K. Koul and Raymond V. Dainty, "Fatigue Fracture of Aircraft Engine Compressor Disks," Rotating Equipment, Handbook of Case Histories in Failure Analysis, Vol. I, pp. 241-250, Apr. 2002. 


\begin{tabular}{|c|c|c|c|c|c|}
\hline \multicolumn{5}{|c|}{ REPORT DOCUMENTATION PAGE } & $\begin{array}{c}\text { Form Approved } \\
\text { OMB No. 0704-0188 }\end{array}$ \\
\hline \multicolumn{6}{|c|}{ 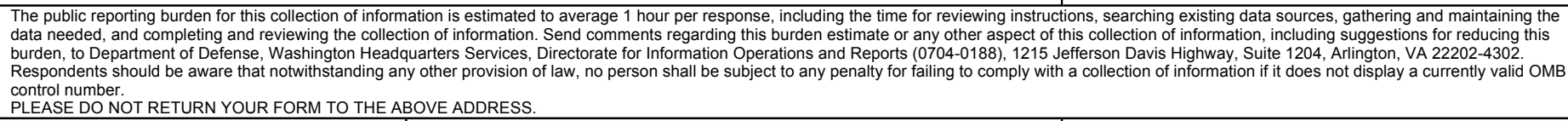 } \\
\hline \multicolumn{2}{|c|}{$\begin{array}{l}\text { 1. REPORT DATE (DD-MM-YYYY) } \\
01-09-2010\end{array}$} & \multicolumn{3}{|c|}{$\begin{array}{l}\text { 2. REPORT TYPE } \\
\text { Technical Memorandum }\end{array}$} & 3. DATES COVERED (From - To) \\
\hline \multirow{3}{*}{\multicolumn{5}{|c|}{$\begin{array}{l}\text { 4. TITLE AND SUBTITLE } \\
\text { Propulsion Health Monitoring of a Turbine Engine Disk Using Spin Test Data }\end{array}$}} & 5a. CONTRACT NUMBER \\
\hline & & & & & 5b. GRANT NUMBER \\
\hline & & & & & 5c. PROGRAM ELEMENT NUMBER \\
\hline \multirow{3}{*}{\multicolumn{5}{|c|}{$\begin{array}{l}\text { 6. AUTHOR(S) } \\
\text { Abdul-Aziz, Ali; Woike, Mark, R.; Oza, Nikunj; Matthews, Bryan; Baaklini, George, Y. }\end{array}$}} & 5d. PROJECT NUMBER \\
\hline & & & & & 5e. TASK NUMBER \\
\hline & & & & & $\begin{array}{l}\text { 5f. WORK UNIT NUMBER } \\
\text { WBS 645846.02.07.03.11.03 }\end{array}$ \\
\hline \multicolumn{5}{|c|}{$\begin{array}{l}\text { 7. PERFORMING ORGANIZATION NAME(S) AND ADDRESS(ES) } \\
\text { National Aeronautics and Space Administration } \\
\text { John H. Glenn Research Center at Lewis Field } \\
\text { Cleveland, Ohio 44135-3191 }\end{array}$} & $\begin{array}{l}\text { 8. PERFORMING ORGANIZATION } \\
\text { REPORT NUMBER } \\
\text { E-17320 }\end{array}$ \\
\hline \multirow{2}{*}{\multicolumn{5}{|c|}{$\begin{array}{l}\text { 9. SPONSORING/MONITORING AGENCY NAME(S) AND ADDRESS(ES) } \\
\text { National Aeronautics and Space Administration } \\
\text { Washington, DC 20546-0001 }\end{array}$}} & $\begin{array}{l}\text { 10. SPONSORING/MONITOR'S } \\
\text { ACRONYM(S) } \\
\text { NASA }\end{array}$ \\
\hline & & & & & $\begin{array}{l}\text { 11. SPONSORING/MONITORING } \\
\text { REPORT NUMBER } \\
\text { NASA/TM-2010-216743 }\end{array}$ \\
\hline \multicolumn{6}{|c|}{$\begin{array}{l}\text { 12. DISTRIBUTION/AVAILABILITY STATEMENT } \\
\text { Unclassified-Unlimited } \\
\text { Subject Categories: } 03 \text { and } 01 \\
\text { Available electronically at http://gltrs.grc.nasa.gov } \\
\text { This publication is available from the NASA Center for AeroSpace Information, 443-757-5802 }\end{array}$} \\
\hline \multicolumn{6}{|c|}{ 13. SUPPLEMENTARY NOTES } \\
\hline \multicolumn{6}{|c|}{$\begin{array}{l}\text { 14. ABSTRACT } \\
\text { This paper considers data collected from an experimental study using high frequency capacitive sensor technology to capture blade tip } \\
\text { clearance and tip timing measurements in a rotating turbine engine-like-disk-to predict the disk faults and assess its structural integrity. The } \\
\text { experimental results collected at a range of rotational speeds from tests conducted at the NASA Glenn Research Center's Rotordynamics } \\
\text { Laboratory are evaluated using multiple data-driven anomaly detection techniques to identify abnormalities in the disk. Further, this study } \\
\text { presents a select evaluation of an online health monitoring scheme of a rotating disk using high caliber sensors and test the capability of the } \\
\text { in-house spin system. }\end{array}$} \\
\hline \multicolumn{6}{|c|}{$\begin{array}{l}\text { 15. SUBJECT TERMS } \\
\text { Rotor dynamics; Spin testing; Dat }\end{array}$} \\
\hline \multicolumn{3}{|c|}{ 16. SECURITY CLASSIFICATION OF: } & $\begin{array}{l}\text { 17. LIMITATION OF } \\
\text { ABSTRACT }\end{array}$ & $\begin{array}{l}\text { 18. NUMBER } \\
\text { OF }\end{array}$ & $\begin{array}{l}\text { 19a. NAME OF RESPONSIBLE PERSON } \\
\text { STI Help Desk (email:help@sti.nasa.gov) }\end{array}$ \\
\hline $\begin{array}{l}\text { a. REPORT } \\
U\end{array}$ & $\begin{array}{l}\text { b. ABSTRACT } \\
U\end{array}$ & $\begin{array}{l}\text { c. THIS } \\
\text { PAGE } \\
\text { U }\end{array}$ & UU & $\begin{array}{l}\text { PAGES } \\
17\end{array}$ & $\begin{array}{l}\text { 19b. TELEPHONE NUMBER (include area code) } \\
443-757-5802\end{array}$ \\
\hline
\end{tabular}



